\title{
OS DESAFIOS DA GESTÃO DEMOCRÁTICA DIANTE DA DIVERSIDADE DAS POLÍTICAS PÚBLICAS PRESENTES NO COTIDIANO ESCOLAR
}

http://dx.doi.org/10.5902/2176217110082

\author{
Camila Moresco Possebon \\ Universidade Federal de Santa Maria, Brasil. \\ Nicole Zanon Veleda \\ Universidade Federal de Santa Maria, Brasil.
}

\begin{abstract}
Resumo
Este trabalho apresenta as reflexões das bolsistas do subprojeto Pedagogia/UFSM/Pibid com o objetivo de propor alternativas de organização escolar que permitam a sistematização das atividades ofertadas no contraturno, para promover a participação efetiva dos alunos. A metodologia adotada é de abordagem qualitativa do tipo pesquisa-ação. Como fonte de dados utilizou-se o controle de frequência e as justificativas das faltas dos alunos. Como referencial teórico foram utilizados estudos de Libâneo (2008) e Freire (1983; 2000) acerca da gestão democrática no contexto escolar. Portanto, conclui-se que traçar estratégias de organização de atividades no turno inverso, atentando para a sua intencionalidade é uma das alternativas de promover a participação efetiva dos alunos nessas atividades.
\end{abstract}

Palavras-chave: gestão democrática, sala multidisciplinar, atividades extracurriculares.

\section{THE CHALLENGES OF MANAGEMENT DEMOCRATIC FRONT OF THE DIVERSITY OF PUBLIC POLICY IN THESE EVERYDAY SCHOOL}

\section{Abstract}

This paper presents the reflections of scholars subproject Pedagogy/UFSM/Pibid aiming to propose alternative school organization enabling the systematization of activities offered in time inverse to promote the effective participation of the students. The methodology is qualitative approach action research. The data source was used the control of frequency and the justification of absences of students. The theoretical studies were used Libâneo (2008) and Freire (1983, 2000) about the democratic management in the school context. Therefore, it is concluded that outline strategies for organizing activities in the opposite shift, noting its intent is an alternative to promote the effective participation of the students in these activities.

Key-words: democratic management; multidisciplinary room; extracurricular activities. 


\section{Introdução}

S reflexões apresentadas ao longo deste trabalho se deram durante o ano de
2012, vivenciadas nas ações desenvolvidas no subprojeto do Programa
Institucional de Iniciação à docência (Pibid), da área da Pedagogia, da Universidade Federal de Santa Maria (UFSM) na condição de bolsistas de iniciação à docência, em uma escola da rede pública de ensino, localizada no bairro Itararé da zona norte do município de Santa Maria, Rio Grande do Sul. Cabe destacar, que o Pibid inserese dentre as políticas públicas para formação de professores propostas pelo governo federal (Brasil, 2012a).

A escola também conta com oficinas do Programa Mais Educação que, conforme o portal do Ministério da Educação (MEC),

aumenta a oferta educativa nas escolas públicas por meio de atividades optativas que foram agrupadas em macrocampos como acompanhamento pedagógico, meio ambiente, esporte e lazer, direitos humanos, cultura e artes, cultura digital, prevenção e promoção da saúde, educomunicação, educação científica e educação econômica. (Brasil, 2012b)

Dessa forma, o programa também é um passo em direção à implementação da Educação Integral que visa universalizar o acesso e permanência dos e das estudantes na escola, oferecendo-Ihes oportunidades que qualifiquem seu rendimento através de espaços de ensino-aprendizagem em articulação com os conteúdos curriculares.

No entanto, a sobreposição de horários dessas atividades causa conflito de interesses das crianças e jovens fazendo com que não possam participar de maneira efetiva em nenhuma delas. Igualmente, os alunos e as alunas encaminhados à sala multidisciplinar apresentam baixa frequência, justificada, muitas vezes, pela participação em oficinas realizadas concomitantemente.

Diante desta sobreposição, a sala multidisciplinar, ofertada no turno inverso para as crianças com dificuldades de aprendizagem e disparidade idade série, encaminhadas pelas docentes das turmas regulares dos anos iniciais do ensino fundamental, tem afetado a participação dos alunos e alunas, comprometendo o alcance dos objetivos do subprojeto, que busca criar espaços alternativos de ensino-aprendizagem com foco nos eixos da lecto-escrita, raciocínio lógico-matemático, localização espaço-temporal e relações interpessoais.

Assim, destaca-se como objetivo deste estudo propor alternativas de organização escolar que permitam a sistematização das atividades desenvolvidas no contraturno da escola. A relevância deste estudo justifica-se pela necessidade de promover a participação efetiva dos alunos no subprojeto Pedagogia/UFSM/Pibid em uma escola pública da rede estadual do município de Santa Maria.

A metodologia adotada partiu do enfoque qualitativo do tipo pesquisa-ação que, segundo Ghedin e Franco (2008, p. 212), "pesquisa e ação podem e devem caminhar juntas, tendo em vista a transformação da prática". Visando compreender os aspectos que podem ser melhorados em conjunto com a gestão da escola em relação à organização das atividades extracurriculares ofertadas no turno inverso do ensino regular, utilizamos como fonte de dados o controle de frequência da Sala Multidisciplinar e as justificativas das faltas dos alunos e das alunas relatadas pelos mesmos ou enviadas em formato de 
bilhetes das famílias ou responsáveis. O tipo de pesquisa adotada para a realização deste estudo

visa intervir na situação, com vistas à modifica-la. O conhecimento visado articula-se a uma finalidade intencional de alteração da situação pesquisada. Assim, ao mesmo tempo que realiza um diagnóstico e a análise de uma determinada situação, a pesquisa-ação propõe ao conjunto de sujeitos envolvidos mudanças que levem a um aprimoramento das práticas analisadas. (Severino, 2007, p. 120)

Nesse contexto, observamos que grande parte das crianças e jovens que frequentavam a Sala Multidisciplinar apresentavam baixa frequência devido as participações esporádicas em outras atividades, que eram ofertadas concomitantemente, daí surgiu a necessidade de pensar estratégias para qualificar e otimizar os tempos e espaços da escola no que se refere às atividades extracurriculares.

Os planejamentos, os relatórios das atividades desenvolvidas, as reuniões de trabalho entre a equipe de bolsistas, professores, direção da escola, coordenação local, e institucional, servem como fonte de dados para proceder as análises do processo de pesquisa em ação desencadeado na escola, posto que as ações são avaliadas diariamente, promovendo a busca de objetivos conjuntos.

\section{A Sala Multidisciplinar como constitutiva do subprojeto da área da Pedagogia}

O Programa Institucional de Bolsas de Iniciação à Docência - Pibid - é uma iniciativa do governo federal para incentivar o exercício do magistério na rede pública de educação através da união entre as escolas estaduais e municipais e as universidades, além de oportunizar o contato dos estudantes de licenciaturas com o cotidiano escolar (Brasil, 2012a). A intencionalidade do Pibid é qualificar o ensino nas escolas, em que o Índice de Desenvolvimento da Educação Básica (Ideb) esteja abaixo da média nacional, por meio dessa parceria que visa o desenvolvimento de práticas inovadoras e diversificadas.

Partindo dessa premissa, o subprojeto Pibid da área da Pedagogia da UFSM atentou para os sistemas de avaliação dos processos de aprendizagem que evidenciam uma situação de fracasso escolar, levando a uma reflexão sobre a formação dos professores que estão atuando nessas escolas e da gestão dos tempos e espaços das mesmas.

A construção de espaços de reflexão-ação-reflexão que promovam a melhoria na qualidade das práticas pedagógicas, a fim de desenvolver plenamente o processo de ensino-aprendizagem é o principal objetivo do subprojeto. Nesses espaços visa-se partir do desenvolvimento das habilidades básicas para a construção do conhecimento a partir das relações interpessoais.

A Sala Multidisciplinar, modalidade de inserção do subprojeto, se caracteriza pelo espaço alternativo de aprendizagem que atende alunos e alunas matriculados nos anos iniciais do ensino fundamental, três vezes por semana no turno inverso ao ensino regular. O grupo se constitui de crianças e jovens que apresentam dificuldades de aprendizagem ou disparidade idade-série, encaminhados através de um parecer descritivo elaborado pelas professoras e professores. O objetivo do parecer é assegurar a intencionalidade da 
sala multidisciplinar, enquanto espaço alternativo de aprendizagem, de maneira que a mesma não se torne mais um depósito de crianças e jovens dentro da escola.

Além de orientar a elaboração de ações pedagógicas relevantes para cada sujeito dentro dos quatro eixos que se baseiam essas ações: raciocínio lógico-matemático (organização mental), lecto-escrita (processo de alfabetização), localização espaçotemporal (noção de tempo e capacidade de localizar-se no espaço dentro de um contexto) e, relações interpessoais (interação entre os sujeitos do meio de convívio), os pareceres descritivos permitem acompanhar o desenvolvimento individual dos sujeitos participantes.

Também se faz um controle da frequência daqueles que participam dos encontros da Sala Multidisciplinar uma vez encaminhados, pois, é necessário que haja uma participação efetiva e regular nas ações pedagógicas realizadas três dias na semana de modo que possamos observar as dificuldades de cada sujeito e suas superações. Entretanto, observou-se no primeiro semestre de 2012 que das quinze crianças e jovens encaminhados apenas em média cinco estavam presentes nos três encontros ou quando não estavam justificavam suas faltas. Os demais estavam em oficinas, no pátio da escola ou tinham ido para casa.

Acreditamos que estes fatos se deram pelo hábito construído pelas crianças e jovens de frequentar aleatoriamente as oficinas oferecidas pelo Programa Mais Educação, nas quais suas participações eram esporádicas. Os gestores da escola acabavam por incentivar tais hábitos de modo que somente asseguravam que estes alunos e alunas estivessem dentro de alguma atividade monitorada, independente das ações planejadas pelos oficineiros.

Foi possível observar nos relatos das crianças e jovens que frequentavam a sala multidisciplinar a influência das relações na escolha das suas atividades diárias. A liberdade em excesso dada aos alunos e alunas gera conflito de interesses entre os gestores da escola e os estudantes, já que em algumas situações esse interesse é diferente entre os grupos envolvidos. Além de a escola oportunizar espaços de desenvolvimento e conhecimentos em diversas áreas, é necessário que a mesma zele para que as crianças e jovens tenham assegurados suas participações nas oficinas ou projetos em que se comprometam em participar. Às crianças e aos jovens, contudo, ficaria o compromisso de responsabilizar-se com as atividades propostas pela oficina.

Considerando que a sala multidisciplinar trabalha com ações pedagógicas que desafiam os sujeitos a superar seus próprios limites, percebemos que em detrimento do esporte, artes e lazer é natural que optem por estas como ferramenta de fuga de suas frustrações através da desestruturação gerada por atividades que exijam persistência, responsabilidade e motivação.

\section{A organização escolar como resultado da gestão educacional mediada pela relação família/escola}

Conforme os estudos de Libâneo (2008) sobre a organização e a gestão da escola é possível identificar o que o autor disserta sobre os traços culturais próprios que refletem dos valores e culturas das pessoas inseridas no meio escolar: gestores, funcionários, alunos, família, professores e comunidade, pois, 
entender a organização escolar como cultura significa dizer que ela é construída pelos seus próprios membros [...]. Membros que tanto podem criar um espaço de trabalho produtivo e até prazeroso ou um espaço hostil e estressante. Não estamos afirmando que na escola não devam existir conflitos, diferenças, interesses pessoais, interesses de poder. Eles existem e, por isso mesmo, é que convêm instalar uma prática de participação, de negociação dos significados e valores, de debate, de discussão pública dos compromissos e dificuldades. (Libâneo, 2008, p. 232)

Dessa forma, a organização escolar também é uma ação educativa para todos os envolvidos levando em consideração as relações deste grupo. Porém, a escola não pode assumir um papel inteiramente assistencialista no que se refere aos cuidados das crianças no tempo em que seus responsáveis estão trabalhando. É preciso que a gestão não fique restrita ao seu papel administrativo e financeiro, em detrimento do papel pedagógico, assegurando que suas estratégias sejam interligadas a partir dos fundamentos de uma rede, bem como prevê o artigo 205 da Constituição Federal (Brasil, 2012c): a educação, direito de todos e dever do Estado e da família, será promovida e incentivada com a colaboração da sociedade, visando ao pleno desenvolvimento da pessoa, seu preparo para o exercício da cidadania e sua qualificação para o trabalho.

É importante que os gestores contemplem a realidade na qual a escola está inserida, que seja flexível para atingir melhores resultados no que diz respeito à formação de cada sujeito como cidadão de uma sociedade. Mas também mais importante é ter coerência entre o discurso e a prática, os aspectos formais e as ações realizadas no gerenciamento da qualidade e otimização dos tempos e espaços da instituição.

A escola, como espaço formal de educação, prima à formação integral das crianças, adolescentes e jovens de modo que os sujeitos construam sua autonomia e transcendam o desenvolvimento das competências nos âmbitos: cognitivo, moral e crítico.

A ação coletiva e solidária, para Paulo Freire, é fundamental para a organização das ações pedagógicas, pois, de maneira que somos seres inacabados e de relação precisamos do outro para existir (Freire, 1983).

Nesse sentido, a escola é aquela que trabalha para a humanização, solidariedade e estímulo da palavra, saber e cultura de todos e todas visando estratégias que unifiquem os seus interesses e é aquela que está no centro da atenção da sociedade, pois há um reconhecimento da educação com fins econômicos, visto que a sociedade globalizada exige o conhecimento científico; a educação é considerada um meio para o desenvolvimento social e da qualidade de vida dos sujeitos.

A oferta de oficinas e espaços dentro da escola no contraturno da aula regular, possivelmente ocupando o tempo em que as crianças e jovens estariam na rua ou sozinhas em casa, é válido quando se tem claramente uma intencionalidade pedagógica para o desenvolvimento pleno da formação do cidadão, pois até mesmo as atividades de lazer precisam ser orientadas em rumo da contribuição ao desenvolvimento humano.

À gestão cabe pensar nessas atividades de contraturno, sejam elas de cunho esportivo, cultural, artístico, entre outras, como uma complementação do ensino formal de modo que também demandem o planejamento adequado e controle de frequência dos participantes, do mesmo modo que a categoria regular de ensino. Pensando na educação do futuro, um futuro que está antecipadamente presente, a escola assume um papel 
fundamental no cotidiano das famílias contemporâneas de ser "um espaço da comunidade e uma de suas funções é organização e formação da comunidade. Muitas vezes é o único espaço público de uma região. O projeto da escola deverá, portanto, incluir a participação dos pais" (Secretaria Municipal de Educação, 1992, p. 23).

Pensar em uma gestão que seja democrática e acolhedora implica em reorganizar o trabalho de dentro da escola, criar espaços e condições de participação das famílias, incentivá-las para os valores do respeito, ética e responsabilidade.

\section{Considerações finais}

Um dos grandes desafios encontrados na gestão das atividades ofertadas no contraturno da escola foi a falta de esclarecimento acerca dos objetivos e metas dos programas e projetos. Outro desafio da gestão é encontrar tempos e espaços de reflexão sobre as ações desenvolvidas, bem como a documentação e sistematização, discussão e socialização dos processos de produção de conhecimento, com todos aqueles que fazem parte dele.

O que observamos no contexto da escola em questão é que a família passa a ser o seu cliente, dentro da perspectiva neoliberal, prestando serviços de assistência e cuidado e em determinados casos, informalizando o espaço institucional e não participando das decisões e discussões com os gestores e o corpo docente. Nesse sentido, a premissa que permeia uma gestão democrática, que permite essas trocas, evidencia a avaliação como um método de monitoramento que qualifica as etapas da construção do conhecimento.

Sem ater as funções da escola a simples processos de ensino-aprendizagem de conhecimentos formais, é necessário reconhecer a relevância da utilização de diversas culturas, a fim de recriá-las. A escola também é local de cuidado e proteção, porém estas precisam ser organizadas e planejadas de modo que qualifiquem 0 ensino e a aprendizagem, expandindo os saberes formais e conhecimentos prévios para a formação crítica e autônoma dos sujeitos.

Para atender todas as funções que a sociedade atribui à escola, como formar cidadão críticos e reflexivos, preparados para o futuro, educá-los e cuidá-los, a escola precisa, conforme Alonso (2003, p. 33) "sofrer alterações estruturais e organizacionais, de forma a ganhar maior flexibilidade e maior coerência com a proposta educacional requerida e almejada".

Pensar questões sobre o que se pretende atingir com cada oficina, ou projeto, planejar as ações desenvolvidas nesse contexto, pensar quem são os sujeitos envolvidos nesse processo é uma alternativa de efetivar a motivação e compromisso destes. A gestão da escola pode prever a participação, além das famílias, professores e alunos, das universidades e outras instituições inseridas no espaço escolar através de projetos e programas.

Esse movimento de troca enriquece os avanços no que diz respeito ao pensar a escola como uma reinventora de culturas em que, o mesmo lugar em que se ensina, é o lugar onde se aprende, ouve, fala, e interage, criando esperanças e possibilidades.

Dentro da perspectiva de uma gestão democrática, traçar estratégias de organização de atividades no turno inverso ao ensino regular, atentando para o seu planejamento e intencionalidade, bem como traçar metas e objetivos, é uma das
Regae: Rev. Gest. Aval. Educ.
Santa Maria
v. 2
n. 3
Jan./jun. 2013
p. 27-34 
alternativas de tentar promover a participação efetiva dos alunos e alunas nessas atividades.

Cabe pensar também, em levantar as demandas das crianças e jovens acerca das atividades garantindo a participação em pelo menos duas delas de modo que consigam inserir-se de maneira plena nos fundamentos de cada oficina ou projeto, atingindo os principais objetivos quanto ao seu desenvolvimento.

Dessa forma, as respostas emergem do olhar atento a todas essas questões, quando nos colocamos como seres produtores de conhecimentos sistematicamente organizados e pensamos nas atividades extracurriculares como tempos e espaços de ampliação do ensino regular, diversificação do currículo e estratégia de qualificar o processo de ensino-aprendizagem de crianças, adolescentes e jovens.

Para atingir o objetivo proposto para esse estudo, de propor alternativas de organização escolar que permitam a sistematização das atividades desenvolvidas no contraturno da escola, acreditamos que as reflexões aqui realizadas nos encaminham para os princípios básicos da gestão democrática, diálogo, compromisso, participação e coerência, esta última como alternativa para diminuir a distância entre o que dizemos e fazemos.

Para Sarturi (2003) as mudanças no cotidiano escolar implicam na participação de toda a comunidade escolar no processo de gestão da escola, apropriar-se das propostas, analisá-las, dialogar entre os segmentos da comunidade escolar são estratégias imprescindíveis para que a organização escolar atenda as expectativas da sociedade, para a qual a superação da prática bancária, bandeira de Paulo Freire durante toda a sua prática pedagógica, é fundamental.

\section{Referências}

ALONSO, Myrtes. A gestão/administração educacional no contexto da atualidade. In: VIEIRA, Alexandre Thomaz; ALMEIDA, Maria Elizabeth Bianconcini; ALONSO, Myrtes (org.). Gestão educacional e tecnologia. São Paulo: Avercamp, 2003, p. 23-38.

BRASIL. Mais educação. Disponível em: <http://portal.mec.gov.br/index.php?ltemid $=467 \&$ id=233\&option=com_content\&view=article $>$. Acesso em: 2 set., $2012 \mathrm{a}$.

BRASIL. Programa institucional de bolsas de iniciação à docência (Pibid). Disponível em: $<$ http://portal.mec.gov.br/index.php?ltemid=467\&id=233\&option=com_content\&view=article> .

Acesso em: 16 ago., 2012b.

BRASIL. Constituição da República Federativa do Brasil de 1988. Disponível em: $<$ http://www.planalto.gov.br/ccivil 03/constituicao/constitui\%C3\%A7ao.htm>. Acesso em: 31 ago., 2012c.

FREIRE, Paulo. A educação na cidade. São Paulo: Cortez, 2000.

FREIRE, Paulo. Pedagogia do oprimido. Rio de Janeiro: Paz e Terra, 1983.

GHEDIN, Evandro. FRANCO, Maria Amélia Santoro. Questões de método na construção da pesquisa em educação. São Paulo: Cortez, 2008.

LIBANEO, Jose Carlos. Organização e gestão da escola: teoria e prática. Goiânia: MF, 2008. 
SARTURI, Rosane C. O processo construção na constituinte escolar: implicações e possibilidade. Porto Alegre: Ufrgs, 2003. Tese (doutorado em Educação). Universidade Federal do Rio Grande do Sul, Faculdade de Educação.

SECRETARIA MUNICIPAL DE EDUCAÇÃO. Construindo a educação pública popular. São Paulo: Município de São Paulo, 1990.

SEVERINO. Antônio Joaquim. Metodologia do trabalho científico. São Paulo: Cortez, 2007.

Camila Moresco Possebon é estudante do curso de Pedagogia (noturno) da Universidade Federal de Santa Maria e bolsista de iniciação à docência do subprojeto/UFSM/Pibid.

Endereço: Rua Aureliano de Figueiredo Pinto, 150/303 - 97050-060 - Santa Maria - RS - Brasil.

E-mail: camis.mp@hotmail.com.

Nicole Zanon Veleda é estudante do curso de Pedagogia (noturno) da Universidade Federal de Santa Maria e bolsista de iniciação à docência do subprojeto/UFSM/Pibid.

Endereço: Rua Elídio Ribeiro, 215 - 97070-114 - Santa Maria - RS - Brasil. E-mail: nicolezveleda@gmail.com.

Recebido em 26 de junho de 2013.

Aceito em 10 de agosto de 2013. 